\title{
Improving Voltage Stability of Power System by Optimal Location of FACTS Devices Using Bio-Inspired Algorithms
}

\author{
Archana Naganathan, Vidhyapriya Ranganathan \\ Department of Information Technology, PSG College of Technology, Coimbatore, India \\ Email: archana.nathan31@gmail.com
}

Received 23 March 2016; accepted 8 May 2016; published 13 May 2016

Copyright (C) 2016 by authors and Scientific Research Publishing Inc.

This work is licensed under the Creative Commons Attribution International License (CC BY).

http://creativecommons.org/licenses/by/4.0/

(c) (i) Open Access

\begin{abstract}
Power system operations can be optimized using power electronics based FACTS devices. The location of these devices at appropriate transmission line plays a major role in their performance. In this paper, two bio-inspired algorithms are used to optimally locate two FACTS devices: UPFC and STATCOM, so as to reduce the voltage collapse and real power losses. Particle swarm optimization and BAT algorithms are chosen as their behaviour is similar. VCPI index is used as a metric to calculate the voltage collapse scenario of the power system. The algorithm is tested on two benchmark power systems: IEEE 118 and the Indian UPSEB 75 bus system. Performance metrics are compared with the system without FACTS devices. Application of PSO and BAT algorithms to optimally locate the FACTS devices reduces the VCPI index and real power losses in the system.
\end{abstract}

\section{Keywords}

BAT, FACTS, Optimal Location, PSO, STATCOM, UPFC, Voltage Stability

\section{Introduction}

With current trends in decreasing fossil fuels, increasing pollution levels, and uncontrolled increase in population, power system optimization is the need of the hour. Various parameters in the power system like voltage, frequency, active and reactive power, harmonic distortion and power factor requires control. Power electronic devices play a major role in optimizing these parameters. With the advent of Flexible AC Transmission (FACTS) Devices, it has become possible to control multiple power system parameters using single device. Thyristor Controlled Series Compensator (TCSC), Static Var Compensator (SVC), Static Synchronous Compensator (STATCOM), Unified Power Flow Controller (UPFC) are few devices that are installed in the power system 
network to enhance controllability and power transfer capability. Each of these FACTS devices provide different benefits to the power system and hence using more than one FACTS device can optimize different parameters, making the power system more reliable. Since real time power systems are huge complex networks with many transmission lines, it is important to find a suitable location for these devices. Placing a FACTS device randomly in a location will not satisfy the objective, and sometimes will produce negative effect on the network.

Many algorithms are used to locate these FACTS devices optimally in the system with different objectives. Genetic algorithm (GA) is widely used to locate FACTS devices. In [1], GA is applied to find optimal location of four FACTS devices namely UPFC, TCSC, TCPST and SVC, with cost as the objective function. Firefly algorithm is used in [2] to locate SVC with power loss and voltage deviation control. Particle Swarm Optimization (PSO) based method [3]-[6] is applied to this problem with different types of objectives in the literature. In [7]-[9], artificial bee colony algorithm is used to locate FACTS devices. To minimize average loadability to relieve overloads, a linear programming [10] and a non-linear programming [11] based optimal location of UPFCs are presented in the literature. A fuzzy [12] approach based optimal location of UPFC under network contingencies is simulated to improve system stability and security. In this paper two types of FACTS devices: UPFC and STATCOM are used as UPFC is one of the best FACTS device, operating under system insecurity [13] [14]. STATCOM is also capable of operating under various stressed conditions of the power system [15] [16]. PSO and BAT algorithms are used to find the optimal location of these devices with multi-objective optimization. Voltage stability and real power loss are considered as optimizing parameters, with voltage deviation penalty. The proposed algorithm is tested on the standard IEEE 118 bus system and the UPSEB 75 bus system with different loading conditions.

\section{Problem Formulation}

Power injection model is used for both STATCOM and UPFC. STATCOM is modeled as a controllable voltage source (Estat $\angle \theta$ stat) in series with an impedance (Ystat) (Figure 1).

Power injection model (Figure 2) is used in this paper, in which UPFC is represented as two voltage sources in steady state between buses $i$ and $j$.

Voltage stability is a major concern in power system, especially during load variations. An accurate and reliable index was proposed by Moghavvemi and Faruque [17] to analyse the stability of the system. Voltage stability proximity indicator is based on the maximum power that is transferred between two nodes in a power system network. It is expressed as in Equation (1) [17].

$$
V C P I=\frac{P}{P_{\max }}=\frac{Q}{Q_{\max }}
$$

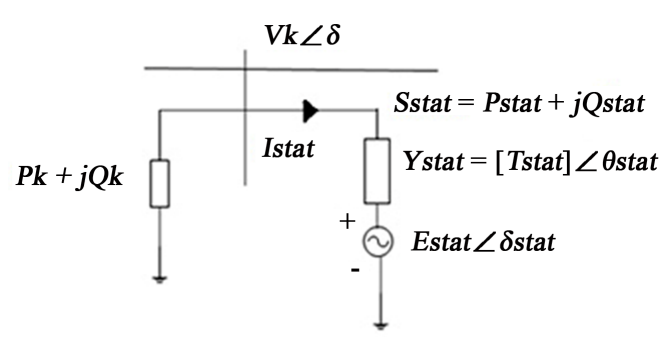

Figure 1. STATCOM steady state model.

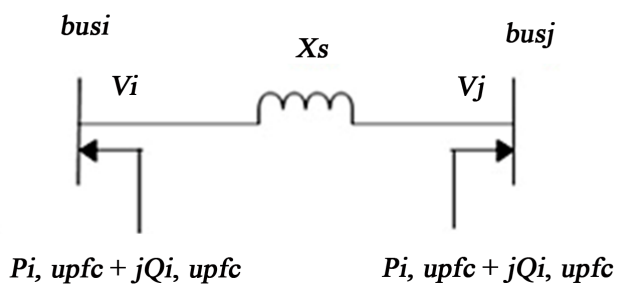

Figure 2. UPFC power injection model. 
where $P, Q$ are the real and reactive power transferred and $P_{\max }$ and $Q_{\max }$ are the maximum values of real and reactive power that can be transferred over a line. The objective of this paper is to reduce the value of VCPI of the power system by using FACTS devices. FACTS devices like STATCOM and UPFC are generally installed in power systems to improve voltage stability. In a large power system network, these FACTS devices can be placed in many possible nodes, and at each location the performance of the system varies. Since real time power system networks are very huge with hundreds of transmission lines, it is not possible to fix these devices with a trial and error method. Also, fixing the FACTS devices at randomly chosen locations may worsen the system performance. Hence this paper proposes two bio-inspired algorithms: PSO and BAT to find an optimal location of these devices so as to improve the system performance. Based on the VCPI metrics, the fitness function for the optimal location is framed as in equation (2)

$$
\text { Fitness function }=f_{1} * \text { VCPI }+f_{2} * \text { Real power loss }+V_{p}
$$

where $f_{1}$ and $f_{2}$ are constants and $V_{p}$ is the voltage penalty that is laid on the equation for crossing voltage limits. Constraints including real and reactive power balance, FACTS installation are considered as given in Equations (3)-(6).

$$
\begin{aligned}
& P_{g i}-P_{d i}-\sum_{j=1}^{N} V_{j}\left[G_{i j} \cos \left(\theta_{i j}\right)+B_{i j} \sin \left(\theta_{i j}\right)\right]=0 \\
& Q_{g i}-Q_{d i}-\sum_{j=1}^{N} V_{i}\left[G_{i j} \sin \left(\theta_{i j}\right)-B i_{j} \cos \left(\theta_{i j}\right)\right]=0 \\
& P_{g i}+P_{\text {factsi }}=P_{d i}+\sum_{j=1}^{n} V_{i} V_{j} Y_{i j}\left[\cos \alpha_{i j}+\theta_{i}+\theta_{j}\right] \\
& Q_{g i}+Q_{\text {factsi }}=Q_{d i}+\sum_{j=1}^{n} V_{i} V_{j} Y_{i j}\left[\cos \alpha_{i j}+\theta_{i}-\theta_{j}\right]
\end{aligned}
$$

where $P_{g i}, Q_{g i}, P_{d i}$ and $Q_{d i}$ are the real and reactive power generated and real and reactive power demand, $P_{f a c t s i}$ and $Q_{\text {factsi }}$ are the real and reactive powers injected/absorbed by FACTS, $V$ is the voltage, $G, B, Y$ are the conductance, susceptance and admittance of the lines. Cost of FACTS devices is also calculated using the Equations (7)-(8) [11].

$$
\begin{aligned}
& \text { cost of statcom }(\$)=\text { Statcom rating in MVar } * 50 \\
& \text { cost of upfc }(\$)=188.2-0.2691 * \text { upfc rating }+0.0003 * \text { upfc rating }{ }^{2}
\end{aligned}
$$

\section{PSO Based Optimal Location}

Particle swarm optimization [18] is a bio-inspired technique, inspired from the intelligent behaviour of a flock of birds moving in search of their food. PSO is a simple algorithm that can solve complex problems, with various boundary conditions in a small time duration. In a PSO algorithm, the swarm interacts in a group which enhances the solution to a problem. Two parameters of a particle: position and velocity, are used as information to travel in the search space. Each particle travels to various locations and saves the value of the best location and velocity obtained so far (Personal best). Similarly a swarm of particles in a society are aware of another value called global best, which is the best value among all personal bests. The position and velocity of each particle is updated for every move, using the equations (9) and (10).

$$
\begin{gathered}
v[i+1]=v[i]+\left\{c_{1} * \text { rand }() *(\text { pbest }[i]-\text { location }[i])\right\}+\left\{c_{2} * \text { rand }() *(\text { gbest - location }[i])\right\} \\
\text { location }[i+1]=\text { location }[i]+v[i]
\end{gathered}
$$

where $v[]$ is the velocity of the particle, location[] is the position of the particle, pbest and gbest are the personal and global best values. $\operatorname{rand}()$ is a random number function that generates values between 0 and $1, c_{1}, c_{2}$ are learning constants, taken as 2 .

The procedure to find an optimal location of FACTS devices using PSO is as follows:

Step 1: Initialize the FACTS devices (STATCOM and UPFC) with random position and size (in MVar). Load the system data: line data, bus data, load power is initially set as $100 \%$. Initialize PSO parameters.

Step 2: For each location, evaluate the VCPI value. 
Step 3: If the VCPI value is better than the previous values, then the position is updated.

Step 4: The VCPI values from all locations are compared and the best value is set as the global best value.

Step 5: The location and size are updated using the standard PSO position and velocity Equations (9) \& (10).

If the value obtained for position is a floating value, then it is rounded off to an integer, as location of FACTS can only be a real number.

Step 6: The process is repeated for a specified number of iterations.

Step 7: The same procedure is again performed for a loading factor of $110 \%$ and $120 \%$.

\section{BAT Based Optimal Location}

BAT [19] is also a bio-inspired algorithm based on the echo location behaviour of microbats. They emit a loud voice and listens for the echo from the surroundings, thereby detecting prays and avoiding obstacles. Similar to the PSO algorithm, BAT algorithm also has two parameters: the position (location[]) and velocity ( $v[])$ of bats. The equation used to determine these values are given in (11) and (12).

$$
\begin{gathered}
v[i+1]=v[i]+\left(\text { location }[i]-\text { location }^{*}\right) f[i] \\
\text { location }[i+1]=\text { location }[i]+v[i+1]
\end{gathered}
$$

where

$$
f[i]=f_{\min }+\left(f_{\min }-f_{\max }\right) \beta
$$

and location ${ }^{*}$ is the global best location of all the bats in the search space. ' $f$ is the frequency assigned to each bat, and $\beta$ is a random vector of $(0,1)$, generated from a uniform distribution. To obtain a new solution for the bats, random walk is used as in equation (14).

$$
\text { location }[\text { new }]=\text { location }[\text { old }]+\epsilon A^{t}
$$

where $\epsilon$ is a random number between $(-1,1)$ and $A$ is the average loudness of all the bats. This local search differentiates BAT from PSO algorithm. FACTS optimal location can be found using BAT algorithm with the following procedure:

Step1: Initialize the FACTS devices (STATCOM and UPFC) with random position and size (in MVar). Load the system data: line data, bus data, load power is initially set as $100 \%$.

Step2: Initialize BAT parameters, frequency, and loudness (Ai), rand and pulse rate ri.

Step3: For each location, calculate the fitness value VCPI.

Step4: Update the position and velocities using relevant equations and frequencies.

Step5: if (rand > ri).

Select a solution among the best solutions.

Generate a local solution around the selected best solution.

Step6: if (rand < ri).

Generate a new solution by flying randomly.

Step7: if (rand < Loudness \& f(location[i]) < f(location*)).

Accept the new solutions Increase ri and reduce Ai.

Step8: Rank the bats and find the current best location*.

\section{Results and Discussions}

The proposed algorithms are tested on the IEEE 118 bus system and the Indian Uttar Pradesh State Electricity Board 75 bus system. The parameter settings of PSO are given in Table 1 and that of BAT in Table 2.

\subsection{Case Study 1: IEEE 118 Bus System}

The IEEE 118 bus system consists of 19 generators, 35 synchronous condensers, 177 lines, 9 transformers and 91 loads. The system is simulated under three loading conditions: full load, $110 \%$ and $120 \%$ of full load, with PSO and BAT algorithms. The VCPI index, real power loss and sizing of the FACTS devices are calculated along with the identification of weak bus (Table 3). Under all loading conditions, PSO performs better than BAT algorithm. The VCPI index of the system without installing FACTS device is 0.4632 . With the installation 
Table 1. PSO parameters.

\begin{tabular}{ccc}
\hline Parameter & Value \\
\hline Population size & 20 \\
C1 & 1.5 \\
C2 & 2.5 \\
Inertia & 0.3 \\
Damp ratio & 0.95 \\
Iterations & 30 \\
\hline
\end{tabular}

Table 2. BAT parameters.

\begin{tabular}{cc}
\hline Parameter & Value \\
\hline Population size & 20 \\
$\mathrm{~A}$ & 0.5 \\
$\mathrm{r}$ & 0.5 \\
Fmin & 0 \\
Fmax & 2 \\
Iterations & 30 \\
\hline
\end{tabular}

Table 3. IEEE 118 system.

\begin{tabular}{|c|c|c|c|c|c|c|c|c|c|c|c|}
\hline \multirow[b]{3}{*}{ Loading } & \multirow[b]{3}{*}{ Algorithm } & \multicolumn{10}{|c|}{ Parameters } \\
\hline & & \multirow[b]{2}{*}{ VCPI } & \multirow[b]{2}{*}{$\begin{array}{l}\text { Weak } \\
\text { line }\end{array}$} & \multicolumn{3}{|c|}{ UPFC } & \multicolumn{3}{|c|}{ STATCOM } & \multirow[b]{2}{*}{$\begin{array}{c}\text { Real } \\
\text { power } \\
\text { loss } \\
\text { (MW) }\end{array}$} & \multirow[b]{2}{*}{$\begin{array}{l}\text { Time } \\
\text { (s) }\end{array}$} \\
\hline & & & & Location & $\begin{array}{c}\text { Size } \\
\text { Voltage } \\
\text { angle }\end{array}$ & $\begin{array}{c}\text { Cost } \\
\text { (US } \$ / k V A r)\end{array}$ & Location & $\begin{array}{c}\text { Size } \\
\text { MVar }\end{array}$ & $\begin{array}{c}\text { Cost } \\
\text { (US } \$ / k V A r)\end{array}$ & & \\
\hline \multirow{4}{*}{100} & No FACTS & 0.4632 & 105 & & & - & & & & 5097 & - \\
\hline & PSO & 0.3506 & 105 & $82-83$ & $\begin{array}{l}0.235 \\
2.999\end{array}$ & 135 & 85 & 4.7 & 62.42 & 3089 & 879 \\
\hline & BAT & 0.3756 & 105 & $50-57$ & $\begin{array}{l}0.208 \\
0.679\end{array}$ & 183 & 57 & 2.095 & 188.0 & 3392 & 5432 \\
\hline & No FACTS & 0.4998 & 105 & & & - & & & & 5632 & - \\
\hline \multirow[t]{3}{*}{110} & PSO & 0.3875 & 105 & $114-115$ & $\begin{array}{l}0.567 \\
0.457\end{array}$ & 183 & 28 & 3.77 & 124.6 & 3572 & 854 \\
\hline & BAT & 0.3936 & 105 & $94-95$ & $\begin{array}{l}0.233 \\
2.447\end{array}$ & 188 & 39 & 0.848 & 199.3 & 3683 & 5120 \\
\hline & No FACTS & 0.5695 & 105 & & & - & & & & 5913 & - \\
\hline \multirow[t]{2}{*}{120} & PSO & 0.4261 & 31 & $114-115$ & $\begin{array}{l}0.210 \\
3.000\end{array}$ & 184 & 40 & 3.77 & 205 & 3788 & 897 \\
\hline & BAT & 0.4592 & 39 & $114-115$ & $\begin{array}{c}0.300 \\
0.00\end{array}$ & 188 & 6 & 3.786 & 250.5 & 3994 & 5876 \\
\hline
\end{tabular}

of FACTS using PSO, there is a reduction of VCPI by $24.3 \%$ and with BAT algorithm by $18.9 \%$. Similarly the real power loss of the system is $5097 \mathrm{MW}$, which is $39.4 \%$ and $33.4 \%$ more when compared to the system with optimally located FACTS device using PSO and BAT respectively.

The algorithms are run for 100 times with the same input conditions and the best, worst and mean values are given in Table 4. 


\subsection{Case Study 2: UPSEB 75 Bus System}

The UPSEB 75 bus system is an Indian Utility system of the state of Uttar Pradesh in India. It includes 15 generators and 98 transmission lines [20]. The results with all types of loading conditions are given in Table 5. The VCPI value without installation of FACTS device is 0.8364 . By optimally locating FACTS devices using PSO and BAT techniques, the VCPI value is reduced to $11.1 \%$ and $7.5 \%$ respectively. The real power losses are also reduced by $79.5 \%$ using FACTS devices with PSO and $79 \%$ using BAT when compared to the system before installation of FACTS (5126 MW). PSO algorithm also obtains the results faster when compared to BAT algorithm.

PSO and BAT algorithms are tested 100 times for each loading conditions and their best, worst and average values are tabulated in Table 6 .

The convergence characteristics of PSO and BAT are given in Figure 3. PSO is seen to converge faster than BAT algorithm. A comparison of voltage profile and VCPI values of each bus obtained using the algorithms is given in Figure 4 and Figure 5. It is observed that PSO performs better than BAT in maintaining the voltage values at 1 p.u. and in decreasing the VCPI values, thereby improving the stability of the system.

Table 4. Output of multiple runs.

\begin{tabular}{cccccccc}
\hline & \multicolumn{9}{c}{ Loading } \\
\cline { 2 - 8 } Values & \multicolumn{3}{c}{$100 \%$} & \multicolumn{3}{c}{$110 \%$} & \multicolumn{3}{c}{$120 \%$} \\
\cline { 2 - 8 } & PSO & BAT & PSO & BAT & PSO & BAT \\
\cline { 2 - 8 } Best & 0.3485 & 0.3700 & 0.3821 & 0.3855 & 0.4155 & 0.4501 \\
Mean & 0.3506 & 0.3756 & 0.3875 & 0.3936 & 0.4261 & 0.4592 \\
Worst & 0.3598 & 0.3799 & 0.3934 & 0.4003 & 0.4376 & 0.4711 \\
\hline
\end{tabular}

Table 5. UPSEB 75 bus system.

\begin{tabular}{|c|c|c|c|c|c|c|c|c|c|c|c|}
\hline \multirow{3}{*}{ Loading } & \multirow{3}{*}{ Algorithm } & \multicolumn{10}{|c|}{ Parameters } \\
\hline & & \multirow[b]{2}{*}{ VCPI } & \multirow[b]{2}{*}{$\begin{array}{l}\text { Weak } \\
\text { line }\end{array}$} & \multicolumn{3}{|c|}{ UPFC } & \multicolumn{3}{|c|}{ STATCOM } & \multirow{2}{*}{$\begin{array}{c}\text { Real } \\
\text { power } \\
\text { loss } \\
(\mathrm{MW})\end{array}$} & \multirow[b]{2}{*}{$\begin{array}{l}\text { Time } \\
\text { (s) }\end{array}$} \\
\hline & & & & Location & $\begin{array}{c}\text { Size } \\
\text { Voltage } \\
\text { angle }\end{array}$ & $\begin{array}{c}\text { Cost } \\
\text { (US } \$ / k V A r)\end{array}$ & Location & $\begin{array}{l}\text { Size } \\
\text { MVar }\end{array}$ & $\begin{array}{c}\text { Cost } \\
\text { (US } \$ / k V A r)\end{array}$ & & \\
\hline \multirow{3}{*}{100} & No FACTS & 0.8073 & 24 & & & - & & & & 5126 & - \\
\hline & PSO & 0.7436 & 24 & $38-39$ & $\begin{array}{l}0.387 \\
0.960\end{array}$ & 143 & 69 & 0.63 & 31 & 1048 & 477 \\
\hline & BAT & 0.7470 & 24 & $36-37$ & $\begin{array}{l}0.400 \\
0.000\end{array}$ & 177 & 75 & 4.76 & 238 & 1071 & 2908 \\
\hline \multirow{3}{*}{110} & No FACTS & 0.8204 & 24 & & & - & & & & 5814 & - \\
\hline & PSO & 0.7581 & 24 & $19-20$ & $\begin{array}{l}0.400 \\
0.000\end{array}$ & 177 & 64 & 2.96 & 148 & 1072 & 494 \\
\hline & BAT & 0.7598 & 6 & $45-44$ & $\begin{array}{l}0.361 \\
1.882\end{array}$ & 184 & 49 & 4.98 & 249 & 1109 & 3108 \\
\hline \multirow{3}{*}{120} & No FACTS & 0.8364 & 24 & & & - & & & & 5906 & - \\
\hline & PSO & 0.7958 & 24 & $19-20$ & $\begin{array}{l}0.393 \\
0.047\end{array}$ & 179 & 74 & 3.32 & 166 & 1241 & 473 \\
\hline & BAT & 0.8145 & 6 & $19-20$ & $\begin{array}{l}0.142 \\
0.428\end{array}$ & 186 & 75 & 5.00 & 250 & 1530 & 3402 \\
\hline
\end{tabular}

Table 6. Robustness measure.

\begin{tabular}{|c|c|c|c|c|c|c|}
\hline \multirow{3}{*}{ Values } & \multicolumn{6}{|c|}{ Loading } \\
\hline & \multicolumn{2}{|c|}{$100 \%$} & \multicolumn{2}{|c|}{$110 \%$} & \multicolumn{2}{|c|}{$120 \%$} \\
\hline & PSO & BAT & PSO & BAT & PSO & BAT \\
\hline Best & 0.7424 & 0.7329 & 0.7330 & 0.7218 & 0.7743 & 0.8108 \\
\hline Mean & 0.7436 & 0.7470 & 0.7581 & 0.7598 & 0.7958 & 0.8145 \\
\hline Worst & 0.7518 & 0.7698 & 0.7789 & 0.7983 & 0.7963 & 0.8198 \\
\hline
\end{tabular}




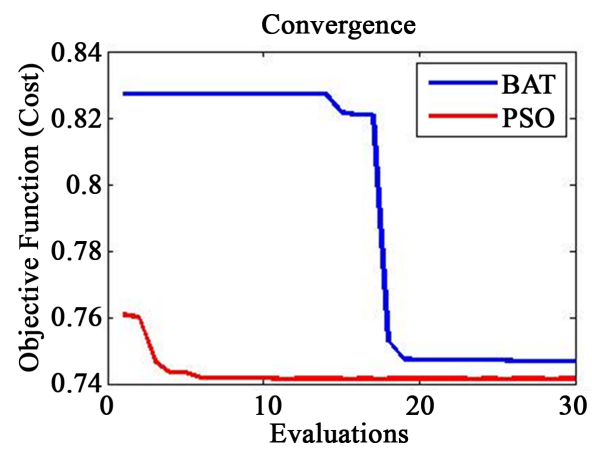

Figure 3. Convergence characteristics of PSO and BAT.

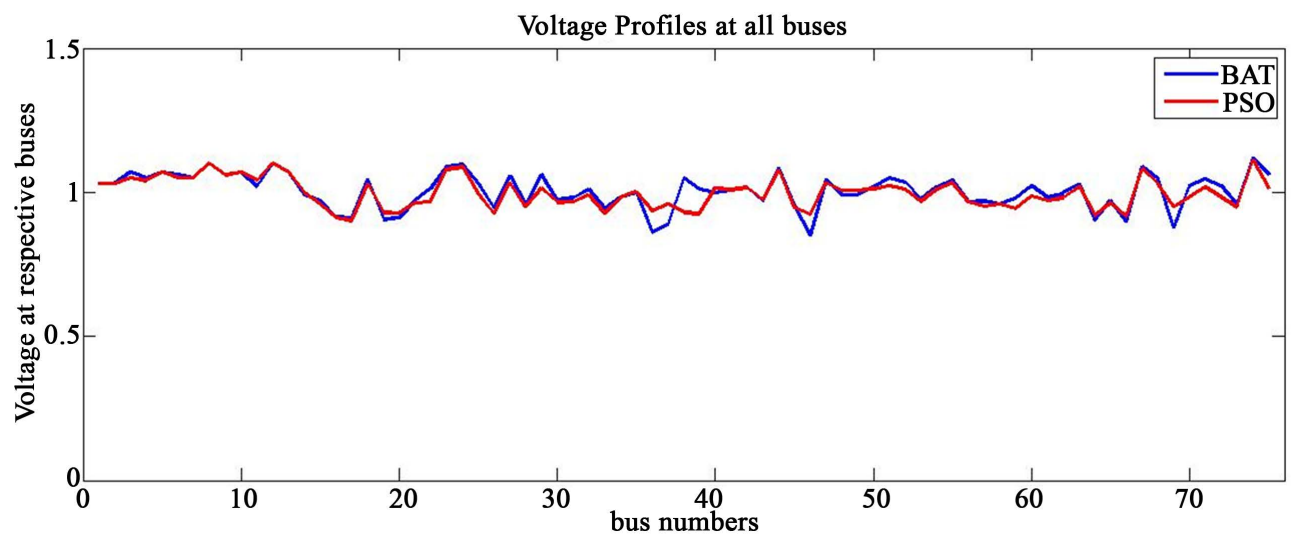

Figure 4. Voltage profile at all bus.

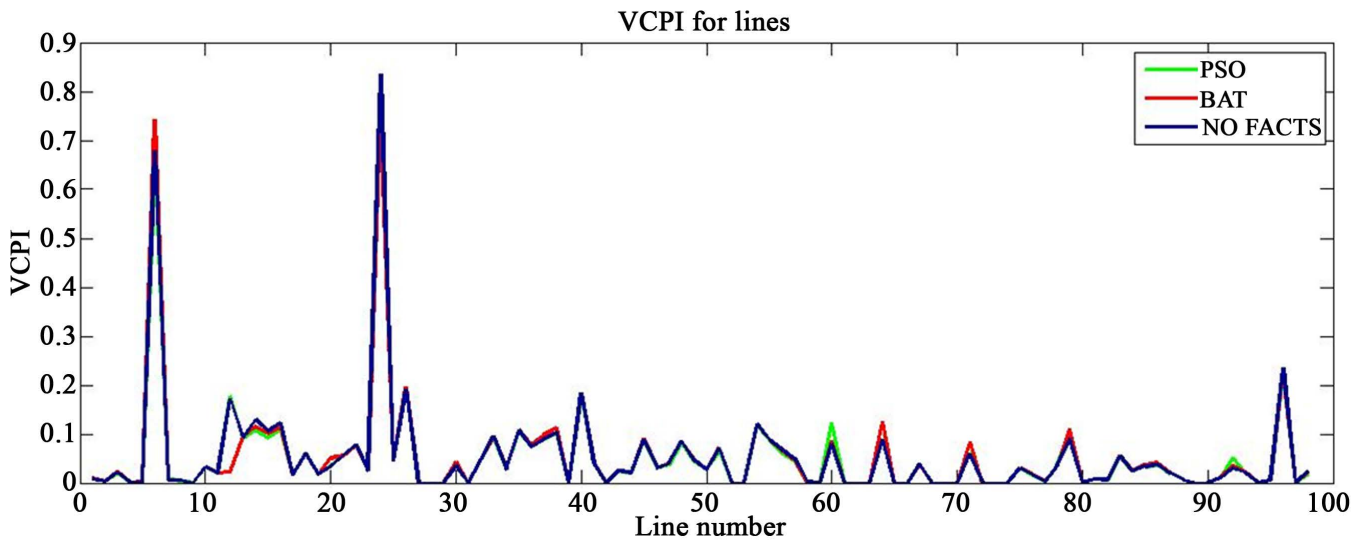

Figure 5. VCPI at each bus.

\section{Conclusion}

Particle swarm optimization and BAT algorithms are successfully used to find a suitable location of multi-type FACTS devices. UPFC and STATCOM, that can perform better than other FACTS devices, are chosen and modeled using power injection model with Jacobian matrix representation. The proposed system is tested on the MATLAB environment using two test cases, IEEE 118 and UPSEB 75 bus system, to validate the proposed objective. Installation of FACTS at appropriate locations using PSO and BAT reduces the VCPI index and real power losses by $18 \%$ and $60 \%$ on an average. Installation of FACTS devices optimizes the power system, but is made more reliable with proper choice of location. PSO algorithm is found to provide better results when compared to BAT algorithm in all aspects. 


\section{References}

[1] Cai, L.J., Erlich, I. and Stamtsis, G. (2004) Optimal Choice and Allocation of FACTS Devices in Deregulated Electricity Market Using Genetic Algorithms. Proceedings of the Power Systems Conference and Exposition, Vol. 1, 201-207. http://dx.doi.org/10.1109/psce.2004.1397562

[2] Rao, B.V. and Kumar, G.V.N. (2014) Sensitivity Analysis based Optimal Location and Tuning of Static VAR Compensator using Firefly Algorithm. Indian Journal of Science and Technology, 7, 201-1210.

[3] Balamurali, G. and Thanushkodi, K. (2011) Novel Selection Factors Based Optimal Placement of TCSC Controller in Power Transmission System for Contingencies Using PSO. Proceedings of the International Conference on Sustainable Energy and Intelligent Systems, Chennai, 20-22 July 2011, 352-357. http://dx.doi.org/10.1049/cp.2011.0388

[4] Tibin, J., Sini, X., Chitra, S. and Cherian, V.I. (2011) PSO Based Optimal Placement and Setting of FACTS Devices for Improving the Performance of Power Distribution System. Bonfring International Journal of Power Systems and Intergrated Circuits, 1, 60-64.

[5] Shaheen, H.I., Rashed, G.I. and Cheng, S.J. (2008) Optimal Location and Parameters Setting of UPFC based on GA and PSO for Enhancing Power System Security under Single Contingencies. Power and Energy Society General Meeting-Conversion and Delivery of Electrical Energy in the 21st Century, Pittsburgh, 20-24 July 2008, 1-8.

[6] Saravanan, M., Slochanal, S.M.R., Venkatesh, P. and Abraham, J.P.S. (2007) Application of Particle Swarm Optimization Technique for Optimal Location of FACTS Devices Considering Cost of Installation and System Loadability. Electric Power Systems Research, 77, 276-283. http://dx.doi.org/10.1016/j.epsr.2006.03.006

[7] Khorsandi, A., Hosseinian, S.H. and Ghazanfari, A. (2013) Modified Artificial Bee Colony Algorithm Based on Fuzzy Multi-Objective Technique for Optimal Power Flow Problem. Electric Power Systems Research, 95, 206-213. http://dx.doi.org/10.1016/j.epsr.2012.09.002

[8] Balarama Krishna Rao, Y.V., Srinivasa Rao, R. and Reddy, V.V.K. (2014) ABC Algorithm Based Comparative Analysis of Optimal SVC and TCSC Placement to Maximize Loadability. International Journal of Electrical and Electronics Engineering Research (IJEEER), 4, 53-64. http://www.tjprc.org/view-archives.php?year=2014_41_2\&id=15\&jtype=2\&page=8

[9] Thangalakshmi, S. and Valsalal, P. (2014) Congestion Management by Optimal Allocation of Facts Controllers Using Hybrid Fish Bee Optimization. Journal of Computer Science, 10, 1766-1775.

[10] Shao, W. and Vittal, V. (2006) LP-Based OPF for Corrective FACTS Control to Relieve Overloads and Voltage Violations. IEEE Transactions on Power Systems, 21, 1832-1839. http://dx.doi.org/10.1109/TPWRS.2006.881127

[11] Lashkar Ara, A., Kazemi, A. and Nabavi Niaki, S.A. (2012) Multiobjective Optimal Location of FACTS Shunt-Series Controllers for Power System Operation Planning. IEEE Transactions on Power Delivery, 27, 481-490. http://dx.doi.org/10.1109/TPWRD.2011.2176559

[12] Visakha, K., Thukaram, D. and Jenkins, L. (2004) Application of UPFC for System Security Improvement under Normal and Network Contingencies. Electric Power Systems Research, 70, 46-55. http://dx.doi.org/10.1016/j.epsr.2003.11.011

[13] Gyugyi, L. (1992) Unified Power-Flow Control Concept for Flexible AC Transmission Systems. IEE Proceedings C, Generation, Transmission and Distribution, 139, 323-331. http://dx.doi.org/10.1049/ip-c.1992.0048

[14] Huang, Z.Y., Ni, Y.X., Shen, C.M., Wu, F.F., Chen, S.S. and Zhang, B.L. (2000) Application of Unified Power Flow Controller in Interconnected Power Systems-Modeling, Interface, Control Strategy, and Case Study. IEEE Transactions on Power Systems, 15, 817-824. http://dx.doi.org/10.1109/59.867179

[15] Teleke, S., Yazdani, A., Gudimetla, B., Enslin, J. and Castaneda, J. (2011) Application of STATCOM for Power Quality Improvement. Power Systems Conference and Exposition (PSCE), Phoenix, 20-23 March 2011, 1-6. http://dx.doi.org/10.1109/psce.2011.5772500

[16] Singh, B., Murthy, S.S. and Gupta, S. (2004) Analysis and Design of STATCOM-based Voltage Regulator for SelfExcited Induction Generators. IEEE Transactions on Energy Conversion, 19, 783-790. http://dx.doi.org/10.1109/TEC.2004.827710

[17] Moghavvemi, M. and Faruque, M.O. (1999) Estimation of Voltage Collapse from Local Measurement of Line Power Flow and Bus Voltages. Proceedings of the International Conference on Electric Power Engineering, Budapest, 29 August-2 September 1999, 77. http://dx.doi.org/10.1109/ptc.1999.826508

[18] Kennedy, J. and Eberhart, R. (1995) Particle Swarm Optimization. Proceedings of the IEEE International Conference on Neural Networks, Vol. 4, 1942-1948. http://dx.doi.org/10.1109/ICNN.1995.488968

[19] Yang, X.-S. (2010) A New Metaheuristic Bat-Inspired Algorithm. In: NatureInspired Cooperative Strategies for Optimization, Studies in Computational Intelligence, Vol. 284, Springer, Berlin, 65-74. 
http://dx.doi.org/10.1007/978-3-642-12538-6_6

[20] Padhy, N.P. and Abdel-Rahim, M.M. (2007) Optimal Placement of Facts Devices for Practical Utilities. International Journal of Power and Energy Systems, 27, 193-204. 